\title{
Atmospheric disturbance on the gas explosion in closed fire zone
}

\author{
Yulong Duan $^{1}$ (1) $\cdot$ Shuo Wang ${ }^{1} \cdot$ Wenhe Wang ${ }^{1} \cdot$ Kai $^{\text {Zheng }}{ }^{2}$
}

Received: 10 September 2019/Revised: 4 November 2019/ Accepted: 2 January 2020/Published online: 5 February 2020

(C) The Author(s) 2020

\begin{abstract}
In order to avoid serious safety accidents caused by closed fire zone, based on the continuous monitoring of atmospheric pressure at different monitoring points in multiple mines, the atmospheric pressure fluctuation model and the air leakage model were established and analyzed. The change law with time of oxygen concentration and gas concentration in the fire zone were obtained due to atmospheric disturbances under the influence of different pressure difference, volume and size of fire area, wind resistance, gas emission, sealing moments, etc. so as to evaluate the explosion risk of a closed fire zone. Research showed that the mine atmosphere fluctuates with the atmosphere of ground, and the pressure difference between the inner and outer sides of the enclosed fire zone is affected by the periodic fluctuation of atmosphere, which has about 16-h cosine fluctuation and approximate 8-h fixed value. Compared with the fire zone with poor sealing quality, good sealing fire zone has better resistance to atmospheric disturbance. The reduction of oxygen concentration in the inner side of a well-sealed fire zone mainly depends on the dilution of methane, which is more likely to accumulate and rise rapidly. And the fire zone with poor sealing quality is easy to be interfered. The inner oxygen concentration and gas concentration are easily affected by the absolute gas emission and the air leakage in the fire zone. Fire zone with small wind resistance and small volume is especially obvious. At the initial stage of the closed fire zone it's very possible to happen explosion. The time duration of explosion danger varies under different conditions, and the atmospheric disturbance may lead to repeated explosions in some cases. It's suggested to take some methods to avoid explosions according to the real-time situation, closure time, oxygen concentration and gas concentration of fire zone.
\end{abstract}

Keywords Fire zone $\cdot$ Early closure time $\cdot$ Atmospheric disturbance $\cdot$ Oxygen concentration

\section{Introduction}

The atmospheric pressure on the ground changes with season, temperature, morning and evening. Then the changes in the surface atmospheric pressure will be quickly transmitted to coal mine, causing the atmospheric pressure at various points in the coal mine to fluctuate with

Yulong Duan

dylnhz@126.com

1 College of Safety Engineering, Chongqing University of Science and Technology, Chongqing 401331, China

2 State Key Laboratory of Coal Mine Disaster Dynamics and Control, Chongqing University, Chongqing 400044, China fluctuations. This phenomenon is called mine breathing effect. Relevant research showed that the mine breathing effect has a significant impact on the underground air pressure (Zhou 2002). Some experts and scholars have also carried out corresponding studies. According to the concept of breathing phenomenon in goaf, $\mathrm{Li} \mathrm{(2012a)}$ analyzed the causes and general rules of this phenomenon, and on this basis, he proposed technical measures to prevent this phenomenon. Guo (2016) studied the relationship between atmospheric pressure changes and gas anomalies caused by changes in seasons and alternation of day and night, and adopted ventilation control of the roadway to resist the abnormal gushing of gas. Through the detection technology of tracer gas, $\mathrm{Li}$ (2012b) found that there is a close 
relationship between the breathing phenomenon in the goaf and the atmospheric pressure change on the ground, which easily causes spontaneous combustion of the remaining coal in the goaf. Zhou (2018) established an experimental platform to monitor and study the combustion state in the fire closed zone of coal mine, and inferred the danger after the fire zone was closed. Therefore, if the fluctuation of pressure that is caused by the breathing effect is not considered, or if it is not considered well, it will bring hidden dangers to safe production of the mine, which may lead to major accidents such as gas accumulation and gas explosion in the closed fire zone. It may bring hidden dangers to the closed and unsealing work of the fire zone (Zhu et al. 2008; Niu et al. 2013; Zhai and Lai 2016; Shi et al. 2017; Zhang et al. 1999). However, the different sealing sequence of fire zone of the coal mine will cause different air flow and gas accumulation in the fire zone, resulting in different hazards in the fire zone (Niu et al. 2016). So, safety issues during the closure of coal mines must be addressed through sound management measures (Adam and Alicja 2018; Arif et al. 2015). How to formulate a set of safety management measures for closed fire zones of mine based on atmospheric changes is very important according to the law of ground atmosphere change.

\section{Analysis on the influence of surface atmospheric pressure on underground pressure in different locations}

Based on the comprehensive detector of mine ventilation parameter, the barometer method is used to measure the difference of absolute static pressure between different points in the well and the ground base point. The variation law of ground and underground atmospheric pressure obtained through monitoring around the clock can be used as an important basic parameter for closing, unsealing and determining the risk of gas explosion in the fire zone. Figure 1 showed the variation of atmospheric pressure at three measuring points. It can be seen that the atmospheric pressure changes of three monitoring points are similar, and the atmospheric pressure is obviously affected by the ground pressure, but there is a weak time difference. Ground pressure changes happened about $30 \mathrm{~min}$ before the underground station, about $40 \mathrm{~min}$ before the fire sealing zone, and the phase difference was approximately $7.5^{\circ}$ and $10^{\circ}$, respectively, while the phase difference between the enclosed fire zone and the outside is only $2.5^{\circ}$. In general, wave transmission is carried out from top to bottom and from near to far. Therefore, it can be approximately considered that the atmospheric pressure outside the closed fire zone changes in a cosine period with the

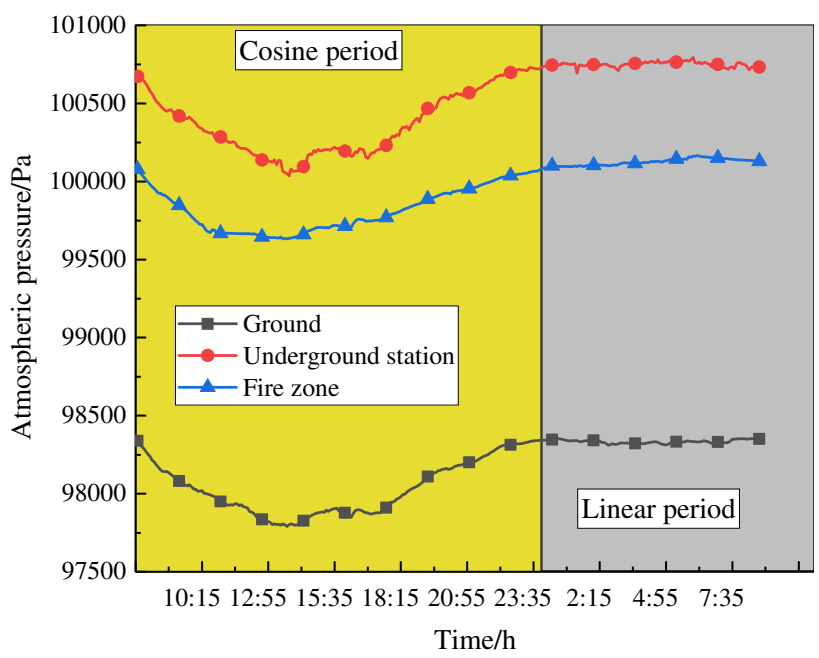

Fig. 1 Continuous monitoring of gas pressure at three different monitoring points in a mine

change of the ground atmosphere, which can be expressed by the mathematical formula as follows:

$P_{\text {out }}=P_{\text {average }}-\Delta P_{\text {out }} \cos 2 \pi \frac{t}{\Delta t}$

where, $P_{\text {out }}$ is the air pressure outside the enclosed zone; $P_{\text {average }}$ is the average pressure; $t$ is the time; $\Delta t$ is the cycle period, and $\Delta P_{\text {out }}$ is the amplitude of pressure change.

Based on Eq. (1), the periodic variation law of pressure with time at three different monitoring points as shown in Fig. 2 is calculated. Comparing Fig. 1 with Fig. 2, it can be seen that Fig. 2 and Fig. 1 have a high degree of repeatability. In Fig. 2, the maximum and minimum values of pressure difference of the three curves are 545, 601, and $518 \mathrm{~Pa}$, respectively. The pressure at three observation points changes approximately in a cosine relationship from

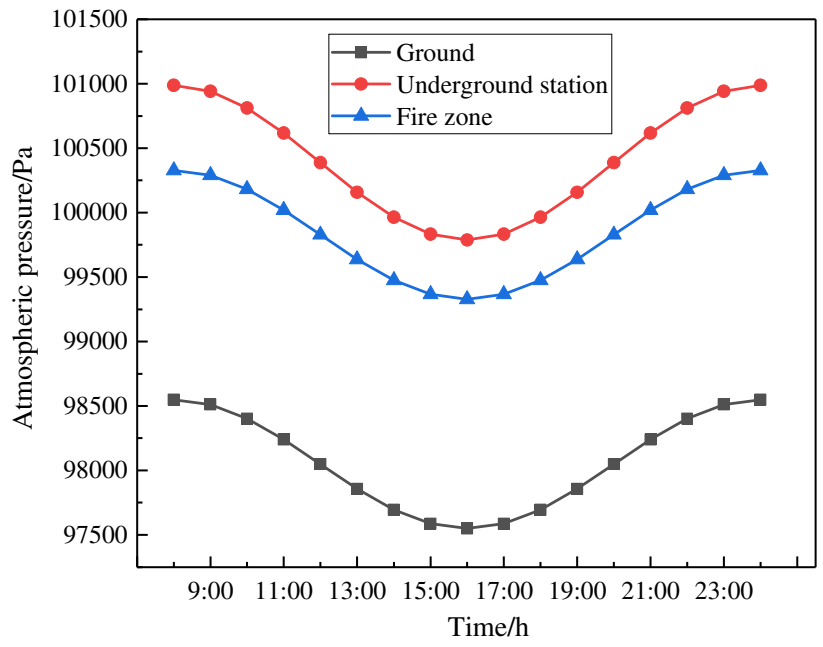

Fig. 2 Analysis on pressure cycle changes of three different monitoring points in a mine 
8:00 a.m. to 24:00 p.m., with a period of about $16 \mathrm{~h}$, which is close to the curve from 8:00 a.m. to 24:00 p.m. in Fig. 1 in terms of trend and value. The atmospheric pressure changes between 24:00 p.m. and 8:00 a.m. is approximately a linear relationship of small fluctuations, which can be expressed as follows:

$P_{\text {out }}=P_{\text {out }, \text { initial }}+k t$

$P_{\text {out }, \text { initial }}$ is the atmospheric pressure at the end of cosine fluctuations, and $k$ is a constant coefficient. When the value of $k$ is small, it can be approximated that the slope is extremely small during linear change. $P_{\text {out }} \approx P_{\text {out }, \text { initial }}$. All the above studies have shown that changes in ground atmospheric pressure have a great impact on underground pressure. Therefore, it is necessary to study how atmospheric pressure changes leading to the temporal and spatial changes of gas flow and components in the closed fire zone, so as to analyze the gas explosion risk in the fire zone under the corresponding state and propose corresponding measures.

\section{Analysis on the influence of ground atmospheric pressure change on air leakage in the closed fire zone}

Although there are different degrees of air leakage in the closed fire zone of mine due to various reasons, the air leakage is generally not substantial. Therefore, it can be assumed that the air in the closed fire zone is laminar flow, and the direction of air leakage is flowing into the fire zone.

$q_{\text {air leakage }}=\frac{1}{R}\left(P_{\text {out }}-P_{\text {closed }}\right)$

where $q_{\text {air leakage }}$ is the air leakage volume, $P_{\text {closed }}$ is the air pressure in the enclosed zone, $P_{\text {out }}$ is the air pressure outside the closed zone, and $R$ is the total air resistance of air leakage passage and firewall.

The change of the air pressure in the closed fire zone from the initial value $P_{\text {outside, initial }}$ reaches $P_{\text {closed }}$ after the time $t$ is expressed as:

$$
\begin{aligned}
\mathrm{d} P_{\text {closed }} & =\frac{q_{\text {air leakage }} \mathrm{d} t}{V} \cdot P_{\text {closed,initial }} \\
& =\left(P_{\text {out }}-P_{\text {closed }}\right) \frac{P_{\text {closed,initial }}}{V R} \mathrm{~d} t
\end{aligned}
$$

Due to $t=0, P_{\text {closed }}=P_{\text {closed,initial, }}$, The above formula can be solved to get:

$P_{\text {closed }}=P_{\text {out }}-\left(P_{\text {out }}-P_{\text {closed,initial }}\right) \exp \left(-\frac{P_{\text {closed,initial }}}{V R} t\right)$

Put Eq. (5) into the Eq. (3): $q_{\text {airleakage }}=\frac{1}{q_{\text {airleakage }}}\left(P_{\text {out }}-P_{\text {closed,initial }}\right) \exp \left(-\frac{P_{\text {closed,initial }}}{V R} t\right)$

where $P_{\text {closed,initial }}$ is the initial air pressure in the closed zone, and $\mathrm{t}$ is the time.

From Eq. (6), it can be seen that the air leakage volume $q_{\text {air leakage }}$ is affected by the air pressure outside the closed zone $P_{\text {out }}$, the air pressure inside the closed zone $P_{\text {closed }}$, and the air leakage channel and total wind resistance $R$ of the fire wall. The air pressure $P_{\text {out }}$ outside the closed zone has been analyzed and studied, which is a periodic variable. The total wind resistance $R$ of the air leakage passage and the firewall represents the shape parameter of the air leakage passage on the closed wall. For the closed fire area of fixed research object, it can be assumed to be a fixed value. The air pressure $P_{\text {closed }}$ in the enclosed area is affected by both $P_{\text {out }}$ and $R$. According to Eq. (6), $\Delta t$ can be inferred from measured data and empirical data. The air leakage amount $q_{\text {air leakage }}$ can be calculated by real-time air pressure outside the closed zone $P_{\text {out }}$, by total wind resistance of the air leakage channel $R$, and by initial air pressure in the closed zone $P_{\text {closed,initial }}$. When the outside pressure is greater than the inside, airflow leaks into the fire area from the outside of the closed fire zone. On the contrary, the airflow in the closed fire zone flows from the return air side to the outside.

It is assumed that the combustion reaction consumption, gas generation, oxygen consumption, adsorption and other comprehensive phenomena in the inner side of the fire zone will not lead to a significant change to air pressure in the fire zone. The pressure change in the fire zone is mainly caused by the external air leakage and internal gas outflow is caused by the pressure difference between the inside and outside. Therefore, it can be considered that the initial pressure inside the fire zone is the same as the pressure outside the fire area because of the moment of complete closure. However, due to many factors such as coal seam cracks and unbalanced sealing quality, it is impossible to realize the real separation between inside and outside the fire zone. There is a relationship between the pressure changes, but there is a certain phase difference. The fluctuation ranges of inside and outside are not the same (When the sealing quality is good and the wind resistance is large, the internal and external pressure difference is large; on the contrary, when the sealing quality is poor and the wind resistance is small, the internal and external linkage is obvious, and the pressure difference is small). According to the quality of closed wall in the fire zone, the values of the total wind resistance $R$ of the air leakage channel are set as follows: $0.5,1,2,3,4,5 \times 10^{4} \mathrm{~N} \mathrm{~s} / \mathrm{m}^{5}$, respectively. At the same time, according to Figs. 1 and 2, as well as 
relevant survey data, considering the measurement error, it is assumed that the pressure difference inside the closed fire area maintains the amplitude of about $600 \mathrm{~Pa}$ and shows cosine fluctuation (Zhou 2002; Guo 2016; Zhou 2018). In combination with formula (6), the relation between air leakage volume and time in the period of cosine cycle variation is shown in Fig. 3. In Fig. 3, according to the actual situation, under different wind resistance settings, the gas exchange between the inner and outer side of fire zone in the changing period caused by the change of pressure difference between the inner and outer side of the closed fire zone is cosine change in the external atmospheric pressure. When the wind resistance is $0.5 \times 10^{4} \mathrm{~N} \mathrm{~s} / \mathrm{m}^{5}$, then the maximum air leakage $q_{\max }=$ $4.8 \mathrm{~m}^{3} / \mathrm{min}$, which are obtained at both ends of the cosine curve respectively. The air leakage in the middle part is small in symmetry. There was no fresh air flowing into the fire zone from 13:00 pm to 19:00 pm. The gas inside part of the fire zone flows back from the return air side to the fire zone. The better the airtightness, the larger the wind resistance. When the wind resistance is $5 \times 10^{4} \mathrm{~N} \mathrm{~s} / \mathrm{m}^{5}$, the maximum air leakage $q_{\max }=0.48 \mathrm{~m}^{3} / \mathrm{min}$. In summary, the more closed the wall, the better the quality, the greater the wind resistance, the smaller the total amount of air leakage into the inner side of the fire zone. The increase of wind resistance has a significant impact on the leakage air volume.

According to Figs. 1, 2, 3 and the above analyses, the period of air leakage from the outside of the fire zone into the inside is from about 8:00 am to 13:00 pm, and from about 19:00 pm to 24:00 pm. The duration of each period is about $6 \mathrm{~h}$. And an approximate linear change phase lasts about $8 \mathrm{~h}$ from about $24 \mathrm{pm}$ to $8 \mathrm{am}$. From about 13:00 pm to $19: 00 \mathrm{pm}$, since the outside atmospheric pressure is

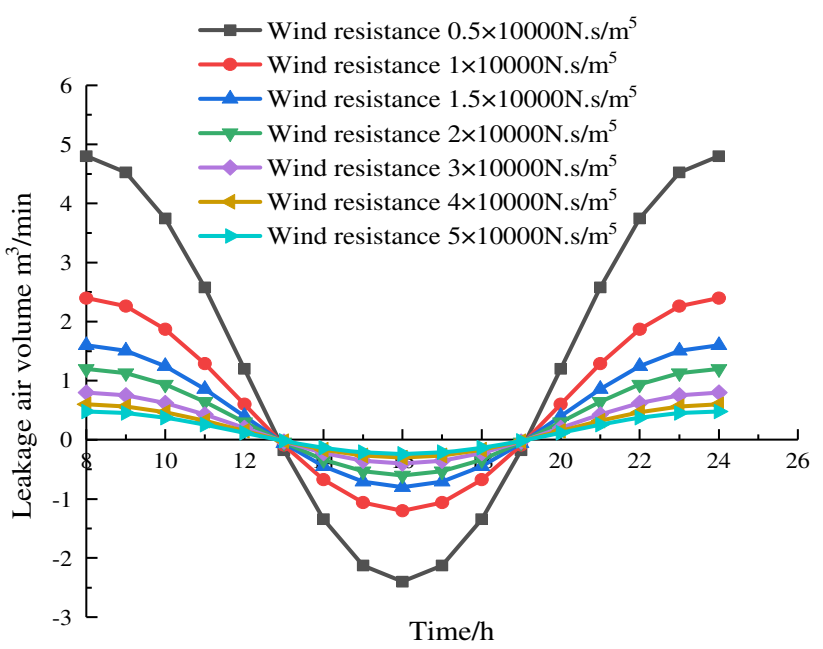

Fig. 3 Real time of air leakage under different wind resistances of single cosine period lower than the inside pressure, almost no fresh airflow enters, and the inner gas escapes from the return air side.

\section{Analysis on explosion risk in the closed fire area with periodic fluctuation of air pressure}

Explosion in a closed fire zone must meet the necessary and sufficient conditions for the explosion, which means the oxygen concentration is above $12 \%$, the gas concentration is between $5 \%$ and $15 \%$, and the superposition can be generated in time and space. For this reason, it is assumed that oxygen and gas in the closed fire zone are in the same space at every moment. This paper starts with the change trend of oxygen concentration and gas concentration in the closed space with time. Analyses and calculations in this paper are made by establishing a mathematical model. This paper also analyzes the size and coincidence degree of knife and fork of the two in time, so as to determine the gas explosion risk in the closed fire zone.

Before solving, it is assumed that all kinds of gases in the air of closed fire zone have been uniformly mixed and there is no chemical reaction, gas adsorption and absorption phenomena. The change in concentration of each gas component in the air of enclosed fire zone can be expressed as follows:

$\mathrm{dC}=\frac{\mathrm{d} t}{V}\left(q_{i}-q_{e} C\right)$

where $C$ is the concentration of an air component in the closed zone, $q_{i}$ is the component flow into a confined fire area affected by real-time air leakage volume), and $q_{e}$ is the mixed gas flow out of the closed fire zone.

Assuming that the boundary condition is $t=0, C=C_{0}$, the above differential equation can be solved:

$C=\frac{q_{i}}{q_{e}}-\left(\frac{q_{i}}{q_{e}}-C_{0}\right) \exp \left(-\frac{q_{e}}{V} t\right)$

The oxygen concentration in the fire zone will reduce by dilution of other gases or oxidation reaction, adsorption and absorption consumption, which of these two types of influences dominate the type of mine fire, after the reduction of the supply of wind, the fire zone spreads and the flow of gas dilutes the air in the fire zone. For small fires in the coal mine with small fire belt (quantity) and large air volume, dilution has a greater impact on the air oxygen concentration than oxygen consumption. Comparing the data of oxygen consumption with that of dilution and consumption, it is found that the influence of oxygen consumption on oxygen concentration can be ignored in most fires with small ignition belts and large air volume (Zhou 2002). Therefore, if only the influences of the double dilution effect of the gas emission from the fire zone and 
the atmosphere pressure outside the fire zone on the methane and oxygen concentration are considered, then, $q_{i}=q_{a} C_{a}$ can be put into Eq. (7) to get:

$\mathrm{d} C=\frac{\mathrm{d} t}{V}\left(q_{a} C_{a}-q_{e} C\right)$

$q_{a}$ is the air flow into the fire zone (different values in different situations), and $C_{a}$ is the oxygen concentration in $q_{a}$ that is $21 \%$.

According to the boundary conditions $t=0, C=C_{a 0}$, and the equation is solved, then the corresponding methane and oxygen concentration at a certain time $t$ after the fire zone is closed can be expressed as follows:

$C=\frac{q_{a} C_{a}}{q_{e}}-\left(\frac{q_{a} C_{a}}{q_{e}}-C_{a 0}\right) \exp \left(-t \frac{q_{e}}{V}\right)$

If the sealing quality is good and there are no cracks in the fire zone, then no air can penetrate the fire zone. $q_{a}=0$, the methane and oxygen concentration $C=C_{a 0} \exp \left(-t \frac{q_{e}}{v}\right)$.

Relevant parameters should be set before calculating the methane and oxygen concentration inside the enclosed fire zone. Combined with the actual situation, it is assumed that $C_{a 0}=0.5 \%$ (initial gas concentration when calculating gas concentration), $C_{a 0}=21 \%$ (initial oxygen concentration when calculating oxygen concentration), $C_{a}=21 \%$, $q_{e}=q_{\mathrm{CH}_{4}}+q_{a} . q_{a}$ is calculated based on Eq. (6), and $q_{\mathrm{CH}_{4}}$ is the absolute gas emission. $10 \mathrm{~m}^{3} / \mathrm{min}$ and $1 \mathrm{~m}^{3} / \mathrm{min}$ are adopted respectively according to high and low gas mines.

\subsection{Analysis on the influence of air pressure fluctuation on oxygen concentration in the closed fire zone}

According to Eq. (10), the oxygen concentration inside the fire zone can be calculated at different times with different volume sizes under the circumstance of closed fire zone (in this paper, taking $V=500,1000,2000,5000,10,000$ and $50,000 \mathrm{~m}^{3}$, respectively). According to Figs. 1, 2 and 3, 13:00 pm, 19:00 pm and 24:00 pm are selected as the closed time for analysis (Zhou 2002; Deng et al. 2004; Zhou et al. 2013, 2015; Wang et al. 2014; Jiao et al. 2012; Duan et al. 2010; Deng et al. 2004; Wang et al. 2003).

Figure 4 shows the change of oxygen concentration in the fire zone from 24:00 at midnight to $13: 00 \mathrm{pm}$ of next day. In this interval, as the pressure difference outside the closed fire zone gradually decreases, the air leakage decreases. It can be seen from Fig. 4a that when the absolute gas emission amount in the fire zone is large, the oxygen concentration in the closed fire region with a relatively small volume rapidly decreases, and the larger fire zone decreases slowly. Among them, $500 \mathrm{~m}^{3}$ fire zone needs about $33 \mathrm{~min}, 1000 \mathrm{~m}^{3}$ fire zone needs about $65 \mathrm{~min}, 2000 \mathrm{~m}^{3}$ fire zone needs about $130 \mathrm{~min}, 5000 \mathrm{~m}^{3}$

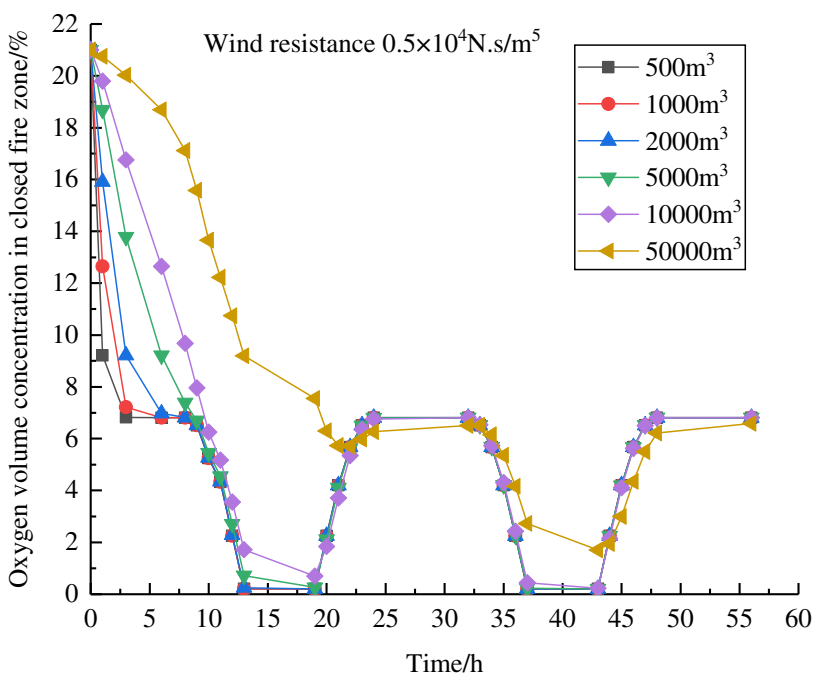

(a) Absolute gas emission in the fire zone $10 \mathrm{~m}^{3} / \mathrm{min}$

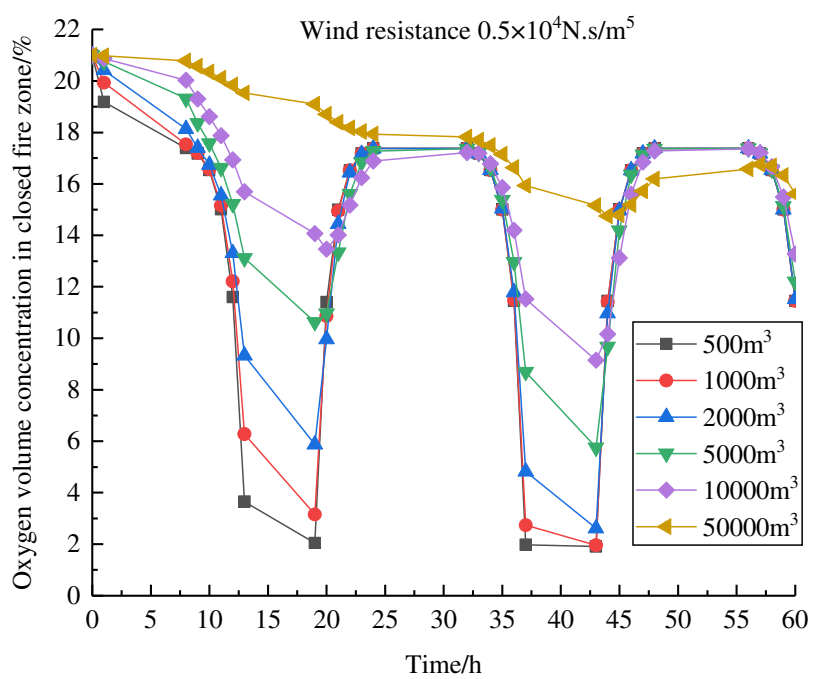

(b) Absolute gas emission in the fire zone $1 \mathrm{~m}^{3} / \mathrm{min}$

Fig. 4 Different gas emission, different fire zone volume, and small wind resistance, the oxygen concentration in the fire zone change with time after the completion of closure at 24:00 midnight are presented

fire zone needs about $240 \mathrm{~min}, 10,000 \mathrm{~m}^{3}$ fire zone needs about $380 \mathrm{~min}, 50,000 \mathrm{~m}^{3}$ fire zone needs about $680 \mathrm{~min}$ to reduce the oxygen concentration in the fire zone to the relatively safe limit of $12 \%$. Except in the case of $50,000 \mathrm{~m}^{3}$, the oxygen concentration in the rest volume of the fire zone will decrease to nearly 0. Except the $50,000 \mathrm{~m}^{3}$ super large fire zone, the oxygen concentration in the fire zone can be reduced to $2 \%$ in all other cases within about $12 \mathrm{~h}$.

It can be seen from Fig. $4 \mathrm{~b}$ that when the absolute gas emission amount in the fire zone is small, the change trend of the oxygen concentration inside the fire zone is similar to the case where the absolute gas emission amount is large. However, it has been estimated that in all cases, the 
oxygen concentration in the fire zone cannot reduce to less than $12 \%$ in a short period of time. If it considers the oxidation and oxygen consumption of the fire zone, it will take more than $360 \mathrm{~min}$ or even more to reduce the oxygen concentration in the fire zone to a safe limit. For safety reasons, inert gas injection is recommended.

Figure 5 is the change of oxygen concentration inside the fire zone from the assumption that the fire zone is completely closed from 19:00 pm to 8:00 am of next day. In this zone, with the passage of time, the pressure difference between the inside and outside of the closed fire zone gradually increased, and the air leakage gradually increased. As seen from Fig. 5a, when the absolute gas

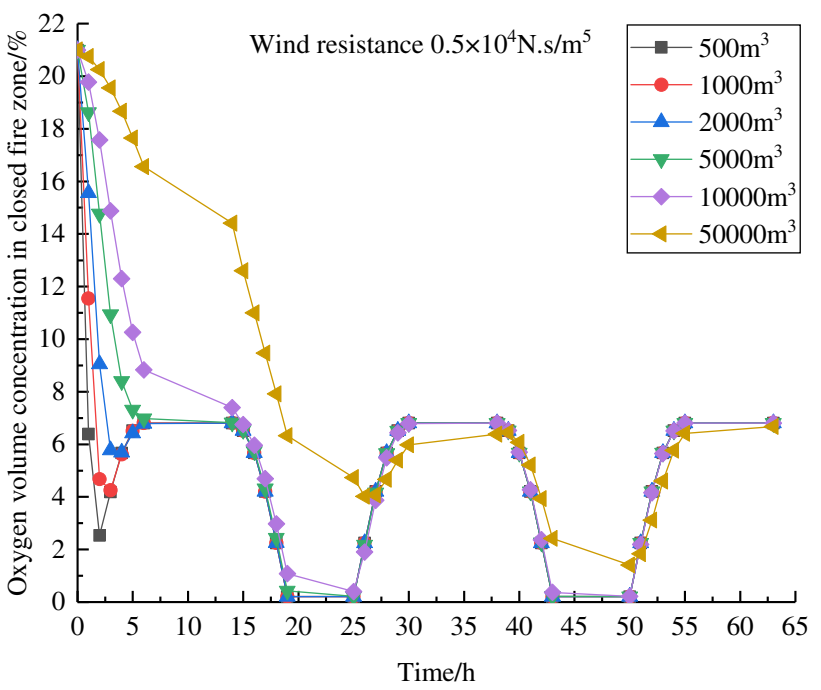

(a) Absolute gas emission in the fire zone $10 \mathrm{~m}^{3} / \mathrm{min}$

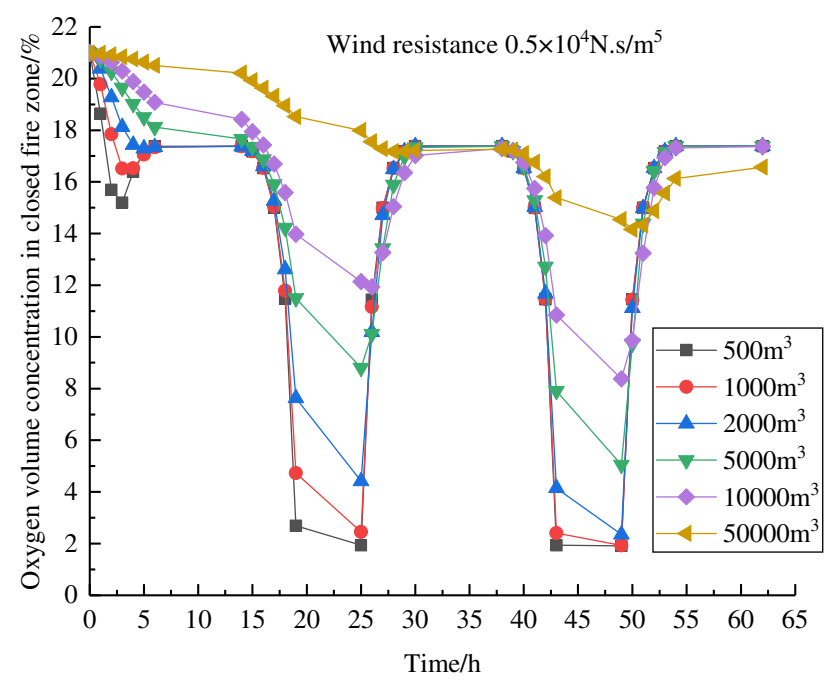

(b) Absolute gas emission in the fire zone $1 \mathrm{~m}^{3} / \mathrm{min}$

Fig. 5 Gas emission, fire zone volume and wind resistance are small. The relationship between oxygen concentration and time in the fire zone after the completion of sealing at 19:00 in the evening is presented emission in the fire zone is large, the oxygen concentration in the relatively small closed fire zone decreases rapidly, while that in the large fire area decreases slowly $500 \mathrm{~m}^{3}$ fire zone needs about $25 \mathrm{~min}, 1000 \mathrm{~m}^{3}$ fire zone needs about $55 \mathrm{~min}, 2000 \mathrm{~m}^{3}$ fire area needs about $100 \mathrm{~min}$, $5000 \mathrm{~m}^{3}$ fire zone needs about $230 \mathrm{~min}, 10,000 \mathrm{~m}^{3}$ fire zone needs about $350 \mathrm{~min}$ to reduce the oxygen concentration. In the $50,000 \mathrm{~m}^{3}$ fire zone, it takes about $660 \mathrm{~min}$ to reduce the oxygen concentration in the fire zone to the relatively safe limit of $12 \%$. In all cases, the oxygen concentration in the fire zone cannot reduce to less than $2 \%$.

It can be seen from Fig. $5 b$ that when the absolute gas emission amount in the fire zone is small, the change trend of the oxygen concentration inside the fire zone is similar to the case where the absolute gas emission amount is large, and the difference is that the required time is different. Moreover, the oxygen concentration in all cases in the figure cannot reduce to less than $12 \%$. If the oxygen concentration in the fire zone reduces to a safe limit in a short time, it is estimated that the volume of the fire zone is less than $200 \mathrm{~m}^{3}$ to satisfy the condition. In the actual conditions, the fire zone is relatively large. Because of the oxidation relationship, there are generally different degrees of oxygen consumption. Therefore, for the $500 \mathrm{~m}^{3}$ situation in Fig. 8b, it is possible to drop oxygen concentration to less than $12 \%$ in about $180 \mathrm{~min}$, and it is possible for $1000 \mathrm{~m}^{3}$ situation to drop oxygen concentration to $12 \%$ in $360 \mathrm{~min}$. It is possible for the situation of below $2000 \mathrm{~m}^{3}$ to drop oxygen concentration to below $12 \%$ after $480 \mathrm{~min}$, and the rest of the larger fire zone will take more than $600 \mathrm{~min}$ to realize it. But for the $50,000 \mathrm{~m}^{3}$ fire zone, it's impossible to realize it. The situation shown in Fig. 8b is only effective in small fire zone. If the oxygen concentration inside the fire zone is completely lower than $12 \%$, the safeguard measure is usually to inject inert gas into the fire zone.

Figure 6 showed the change of oxygen concentration inside the fire zone from the time that the fire zone was completely closed, which is 13:00 to 8:00 of next morning. As it can be seen from Fig. 6a, when the absolute amount of gas gushing out of the fire zone is very large, the oxygen concentration trend in the $50,000 \mathrm{~m}^{3}$ super-large fire zone always reduces to a certain level and maintains stable, and the oxygen concentration trend in other types of fire zones first decreases and then recovers to a certain level and maintains stable. It only took $28 \mathrm{~min}$ for oxygen concentration of $500 \mathrm{~m}^{3}$ fire zone reducing to $12 \%$. The capacity of oxygen concentration diluted to $0 \%$ in $180 \mathrm{~min}$. As for $1000 \mathrm{~m}^{3}$ fire zone, it took about $55 \mathrm{~min}$ reducing to $12 \%$, and the capacity of oxygen concentration completely diluted in $360 \mathrm{~min}$. Likewise, it took about $110 \mathrm{~min}$ for $2000 \mathrm{~m}^{3}$ fire zone needs reducing to $12 \%$, and $420 \mathrm{~min}$ for complete dilution. It took about $220 \mathrm{~min}$ for $5000 \mathrm{~m}^{3}$ fire 


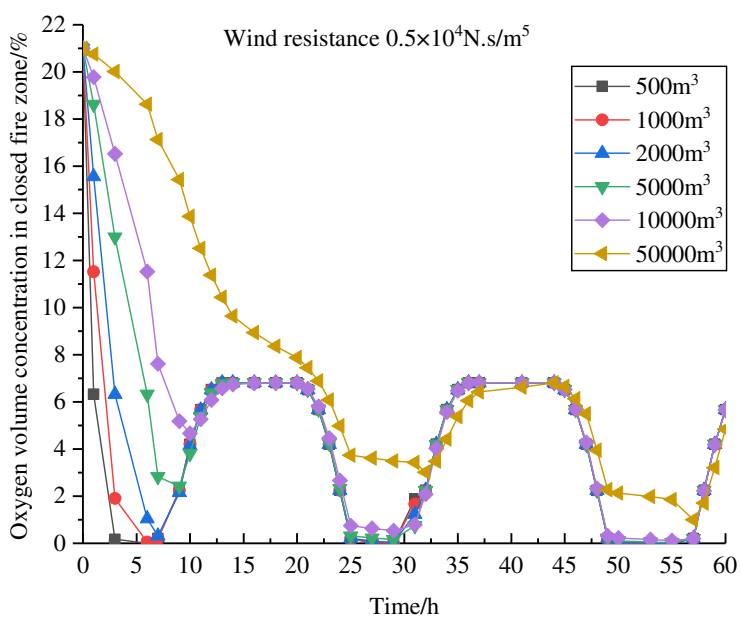

(a) Absolute gas emission in the fire zone $10 \mathrm{~m}^{3} / \mathrm{min}$

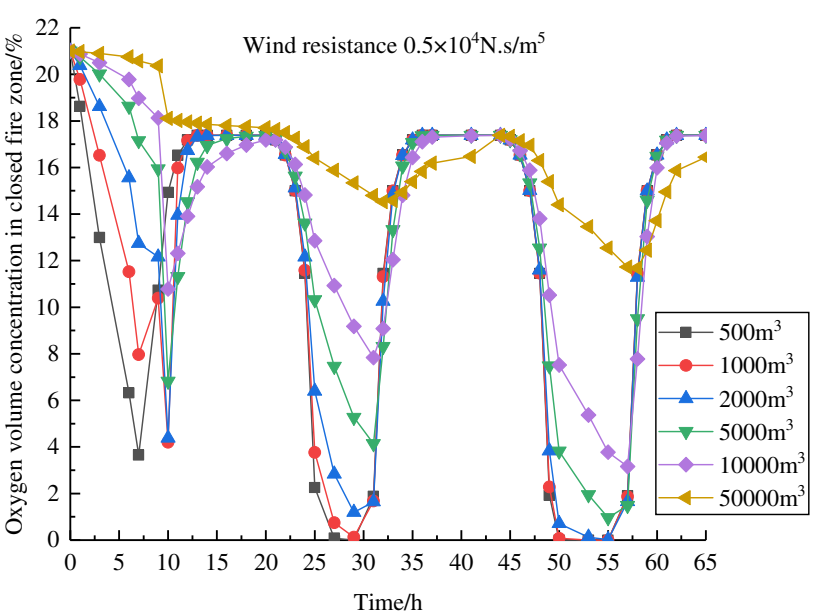

(b) Absolute gas emission in the fire zone $1 \mathrm{~m}^{3} / \mathrm{min}$

Fig. 6 The relationship between the gas emissions in different fire zone, the volume of different fire zone, and the small wind resistance is presented. The oxygen concentration in the fire zone changes with time after the completion of closure at 13:00

zone reducing to $12 \%$, and $540 \mathrm{~min}$ for dilution to $2.4 \%$. It took about $320 \mathrm{~min}$ for $10,000 \mathrm{~m}^{3}$ fire zone reducing to $12 \%$, and $600 \mathrm{~min}$ for dilution to $4.7 \%$. Finally, the oxygen concentration inside the above-mentioned several types of fire zone will temporarily stabilize at around $6.8 \%$. The oxygen concentration in the oversized fire zone of $50,000 \mathrm{~m}^{3}$ needs to reduce to about $12 \%$ within $680 \mathrm{~min}$, and temporarily stabilized at about $7.9 \%$. The oxygen concentration in the smaller fire zone can reduce to less than $2 \%$ between 3 and $6 \mathrm{~h}$.

It can be seen from Fig. $6 \mathrm{~b}$ that when the absolute gas emission in the fire zone is very small, the oxygen concentration change inside the fire zone first decreases to lower than $12 \%$, and then quickly rises to higher than $12 \%$, which both have experienced two dangerous areas. The oxygen concentration of $500 \mathrm{~m}^{3}$ in the fire zone dropped to $12 \%$ about within $220 \mathrm{~min}$, and then it dropped as low as
$3.7 \%$. After about $6 \mathrm{~h}$, it returned to higher than $12 \%$ again and temporarily stabilized around $17.4 \%$. The oxygen concentration in the $1000 \mathrm{~m}^{3}$ fire zone decreased to $12 \%$ about within $320 \mathrm{~min}$, and thereafter it was as low as $4.2 \%$. After about $4 \mathrm{~h}$, it returned to higher than $12 \%$ again and temporarily stabilized at around $17.4 \%$. The oxygen concentration in the $2000 \mathrm{~m}^{3}$ fire zone decreased to $12 \%$ about within $560 \mathrm{~min}$, and then decreased to the lowest $4.4 \%$. After about $1.5 \mathrm{~h}$, it returned to higher than $12 \%$ again and temporarily stabilized at around $17.4 \%$. The oxygen concentration in the $5000 \mathrm{~m}^{3}$ fire zone decreased to $12 \%$ about within $570 \mathrm{~min}$, and thereafter it decreased to as low as $6.8 \%$. After about $1 \mathrm{~h}$, it returned to higher than $12 \%$ again and temporarily stabilized at around $17.4 \%$. The oxygen concentration in the $10,000 \mathrm{~m}^{3}$ fire zone decreased to $12 \%$ about within $580 \mathrm{~min}$, and then decreased to the lowest $10.8 \%$. After about $1 \mathrm{~h}$, it returned to higher than $12 \%$ again and temporarily stabilized at around $17.4 \%$. The oxygen concentration in the $50,000 \mathrm{~m}^{3}$ fire zone temporarily stabilized after it reduced to $17.7 \%$.

In the same way, three different moments were taken to study the change law of oxygen concentration in the initial stage of fire zone closure under the condition of wind resistance is $5 \times 10^{4} \mathrm{~N} \mathrm{~s} / \mathrm{m}^{5}$, as shown in Figs. 7, 8, 9 . Comparative analysis brings the following three conclusions: (1) For the same sealing effect (the same as the wind resistance), the oxygen concentration in the fire zone with a large amount of gas emission has better resistance to external atmospheric disturbance than that with a small amount of gas emission. The fluctuation range is smaller, and the oxygen concentration in the fire zone reduced to a lower range more quickly. (2) For the outer closed case at the same time, the oxygen concentration in the fire zone with a large amount of gas emission is stronger and more stable than that in the fire zone with a small amount of gas emission, and the value is more stable. When the amount of gas emission in the fire zone is small, the external atmosphere has a strong interference to the oxygen concentration in the fire zone, which is likely to cause a repeated over-limit of $12 \%$ of the oxygen concentration in the fire zone. When the gas emission in the fire area is large, although it is also subject to fluctuations in the external atmosphere, the fluctuation range is relatively small, and there is basically no possibility of repeating again to higher than $12 \%$. This is especially true for the completion of closure at 13:00. (3) For the same gas emission amount, the oxygen concentration in the fire zone reduced to a lower value in the case of greater wind resistance than that in the case of smaller wind resistance, and the rebound amplitude was small. 


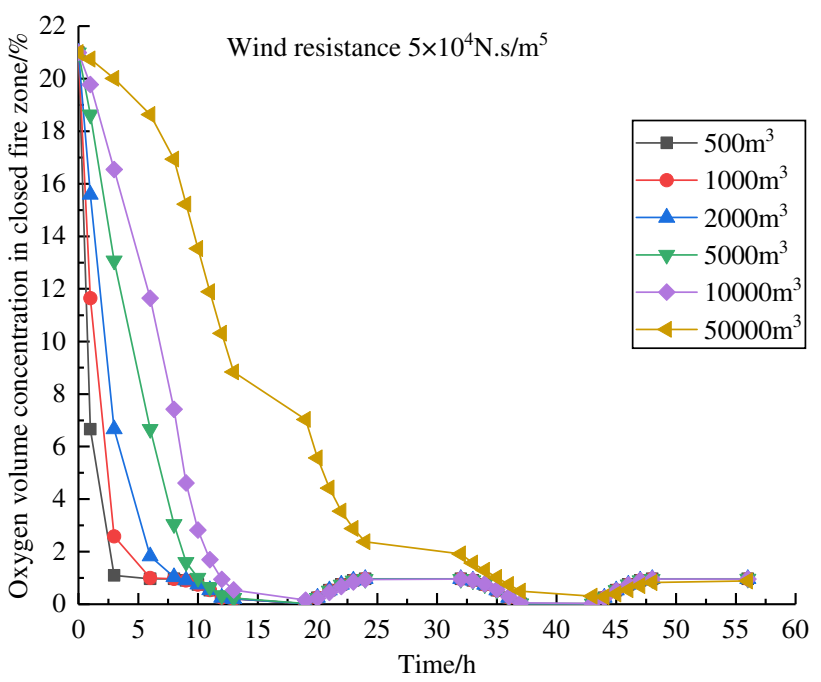

(a) Absolute gas emission in the fire zone $10 \mathrm{~m}^{3} / \mathrm{min}$

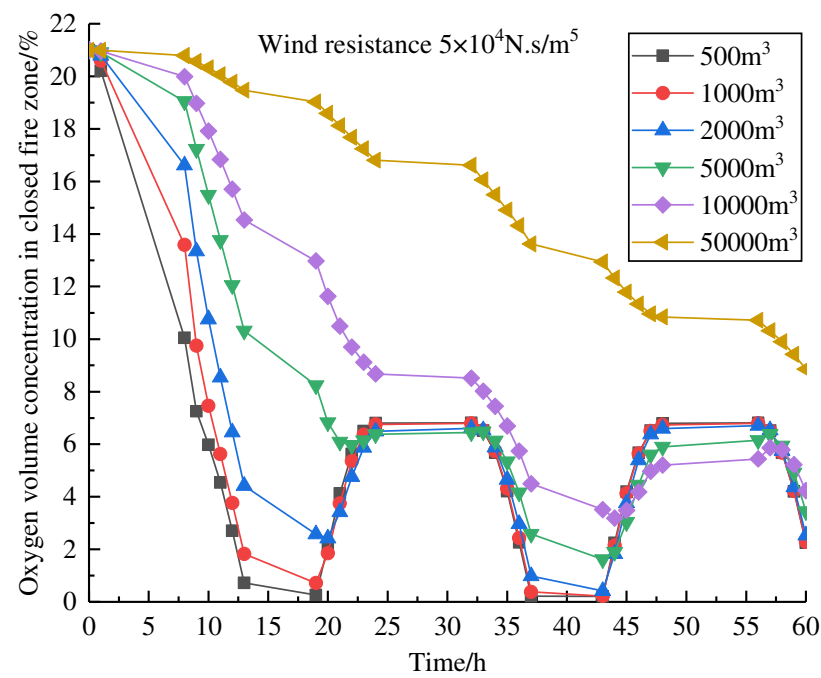

(b) Absolute gas emission in the fire zone $1 \mathrm{~m}^{3} / \mathrm{min}$

Fig. 7 Different gas emission, different fire area volume, and large wind resistance, the relationship between oxygen concentration and time in the fire zone after the closing at 24:00 in the middle of the night

\subsection{Analysis on the influence of pressure fluctuation on gas concentration in the closed fire zone}

Figure 10 showed the changes of gas concentration inside the fire zone for a period of time after the fire zone is completely closed from 24 o'clock in the middle of the night. It can be seen from Fig. 10a that when the absolute gas emission amount in the fire zone is large, the gas concentration in the closed fire zone with relatively small volume rises rapidly, and the larger fire zone rises relatively slowly. 500, 1000, 2000, 5000, 10,000 and $50,000 \mathrm{~m}^{3}$ fire zones reach the lower limit of $5 \%$ explosion time about in $2.5,5,10,25,45,180 \mathrm{~min}$, respectively. The

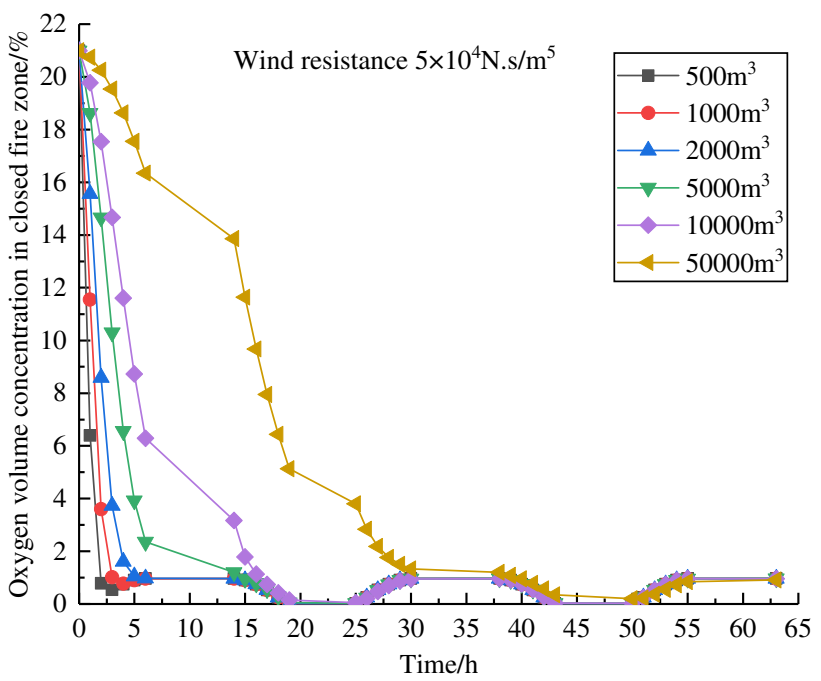

(a) Absolute gas emission in the fire zone $10 \mathrm{~m}^{3} / \mathrm{min}$

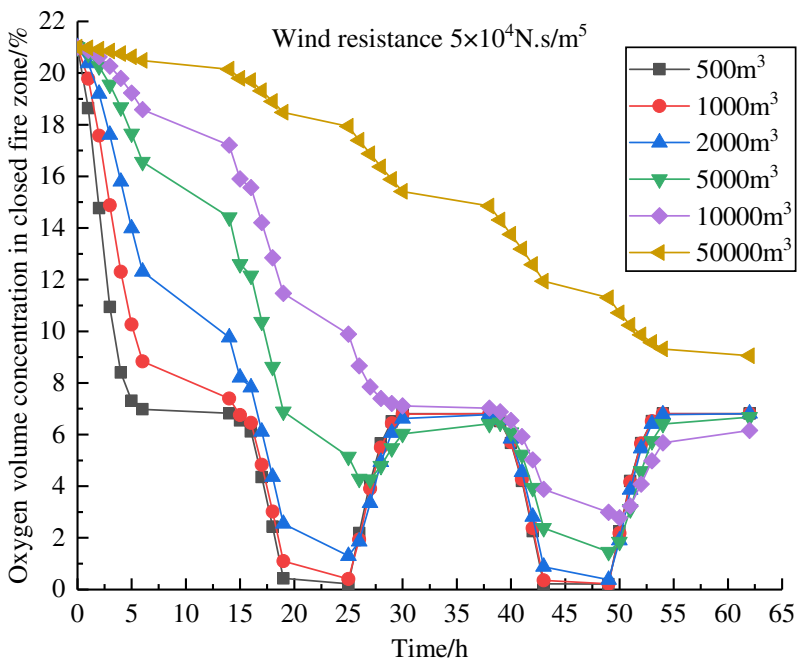

(b) Absolute gas emission in the fire zone $1 \mathrm{~m}^{3} / \mathrm{min}$

Fig. 8 Different gas emission, different fire area volume, wind resistance, and the relationship between oxygen concentration and time in the fire zone after the completion of sealing at 19:00

time to reach the maximum explosion concentration of $15 \%$ was about $8,16,32,80,110$ and $580 \mathrm{~min}$, respectively. The duration of explosion risk concentration was about 5.5, 11, 22, 55, 65 and $400 \mathrm{~min}$, respectively. In Fig. 10b, 500, 1000, 2000, 5000, 10,000, and 50,000 $\mathrm{m}^{3}$ fire zones reach the lower limit of $5 \%$ explosion time was about in 30, 55, 100, 210, 480, $720 \mathrm{~min}$, respectively. The time to reach the maximum explosion concentration of $15 \%$ was about 120, 280, 560, 630, 700, $1440 \mathrm{~min}$, respectively. The duration of explosion risk concentration was about 90, 225, 450, 420, 320, and $720 \mathrm{~min}$, respectively. It can be seen that the smaller the volume of the closed fire zone is, the earlier the concentration limit of gas explosion will reach, but the duration is relatively short. In 


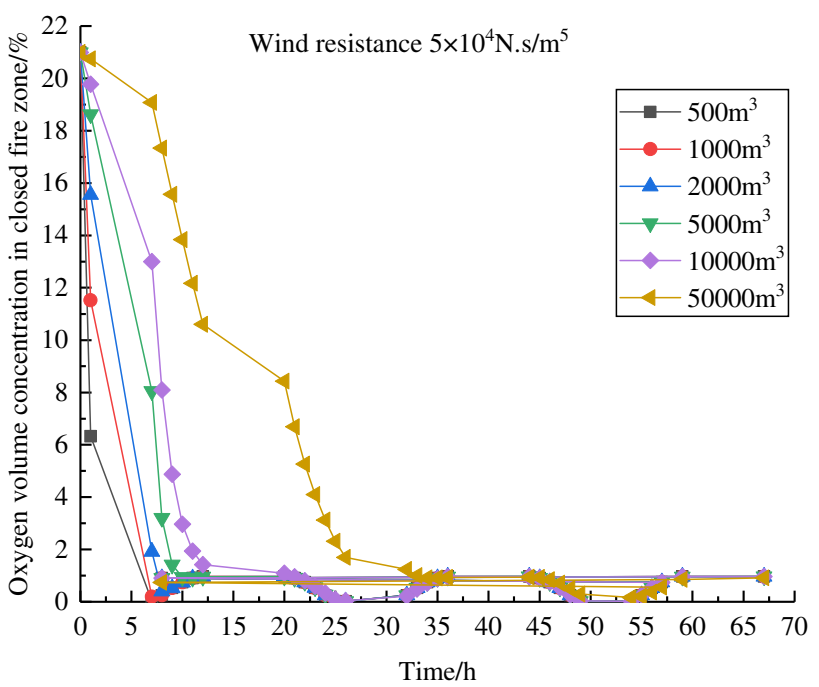

(a) Absolute gas emission in the fire zone $10 \mathrm{~m}^{3} / \mathrm{min}$

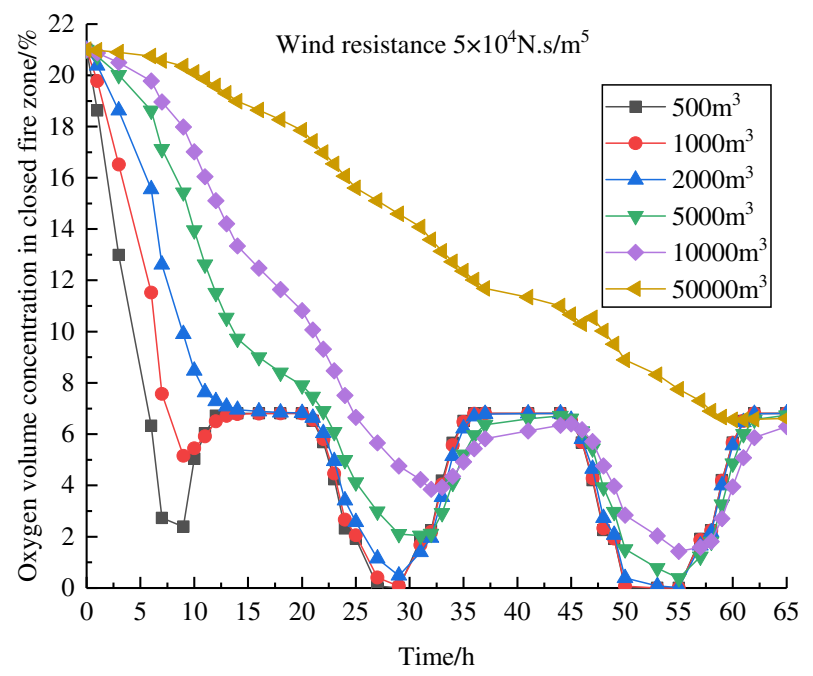

(b) Absolute gas emissionin the fire zone $1 \mathrm{~m}^{3} / \mathrm{min}$

Fig. 9 The different gas emission, different volume of fire zones, and large wind resistance. The relationship of oxygen concentration in the fire zone changing with time after the completion of sealing at 13:00

the fire zone with a large amount of gas emission, the gas concentration rises much faster than that in the fire area with a small amount of gas emission. The time to reach the explosion limit is shorter, the lasting time of explosion is shorter, and the danger is relatively smaller.

Figure 11 is the change of gas concentration in the fire zone within a period of time after the complete closure of the fire zone was assumed from 19:00. It can be seen from Fig. 11a, 500, 1000, 2000, 5000, 10,000 and 50,000 $\mathrm{m}^{3}$ fire zones reach the lower limit of $5 \%$ explosion time about in $2.5,4.5,9.5,23,45,140 \mathrm{~min}$, respectively. The time to reach the maximum explosion concentration of $15 \%$ was about $7.5,15.5,31.5,78.5,100$, and $280 \mathrm{~min}$, respectively. The duration of explosion risk concentration was about 5 ,

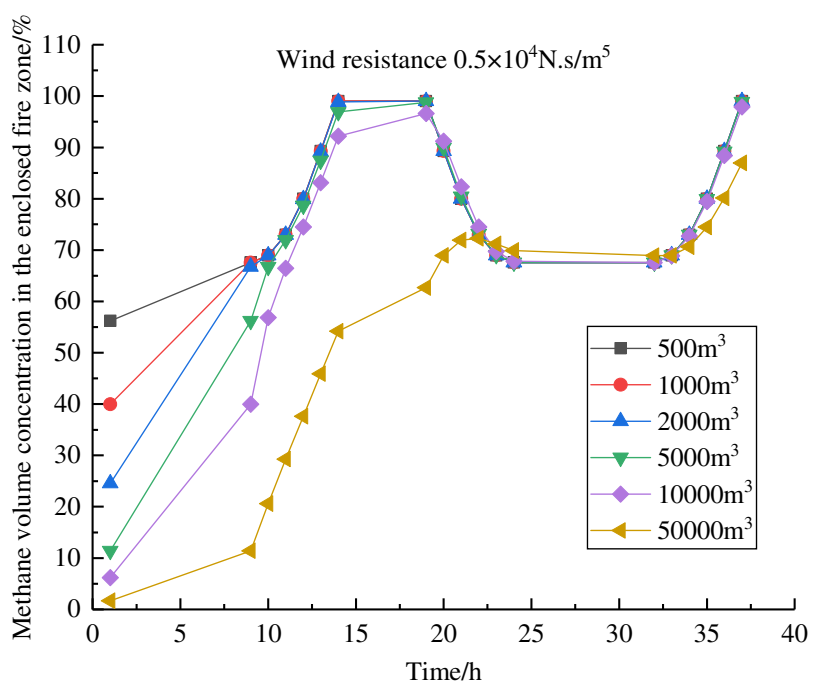

(a) Absolute gas emission in the fire zone $10 \mathrm{~m}^{3} / \mathrm{min}$

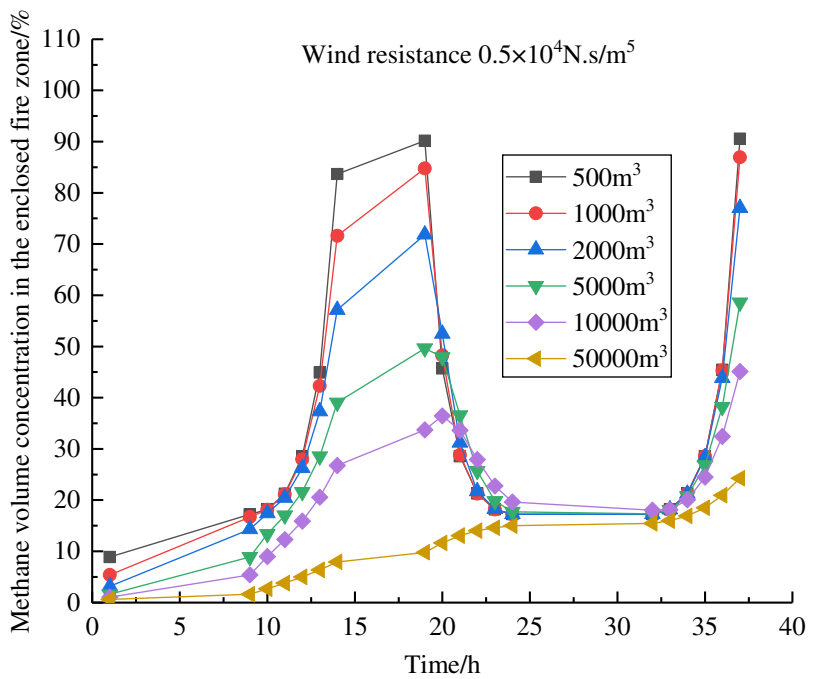

(b) Absolute gas emission in the fire zone $1 \mathrm{~m}^{3} / \mathrm{min}$

Fig. 10 The changes of different gas emission, different fire zone volume, and small wind resistance, the gas concentration in the fire zone with time after the completion of closing at 24:00 midnight

11, 22, 55, 55, 140 min, respectively. In Fig. 11b, 500, $1000,2000,5000,10,000$ and $50,000 \mathrm{~m}^{3}$ fire zones reach the lower limit of $5 \%$ explosion time about in $23,48,95$, $130,210,870 \mathrm{~min}$, respectively. The time to reach the maximum explosion concentration of $15 \%$ was about 80 , $115,200,660,920$, and $1520 \mathrm{~min}$, respectively. The duration of explosion risk concentration was about 57, 67, $105,450,710,650 \mathrm{~min}$, respectively. After about $30 \mathrm{~h}$, the concentration of all types fluctuates again to $17 \%-18 \%$. In case of damage caused by poor quality of airtight wall or other reasons, the leakage of fresh air may cause to reach the upper limit of explosion.

Figure 12 showed the variation of gas concentration inside the fire zone for a period of time after the fire zone is 


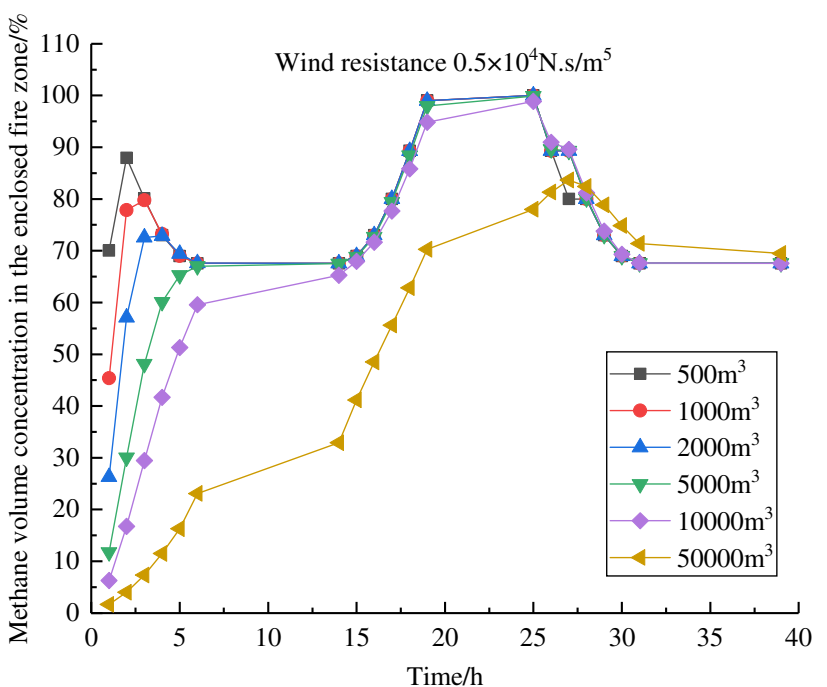

(a) Absolute gas emission in the fire zone $10 \mathrm{~m}^{3} / \mathrm{min}$

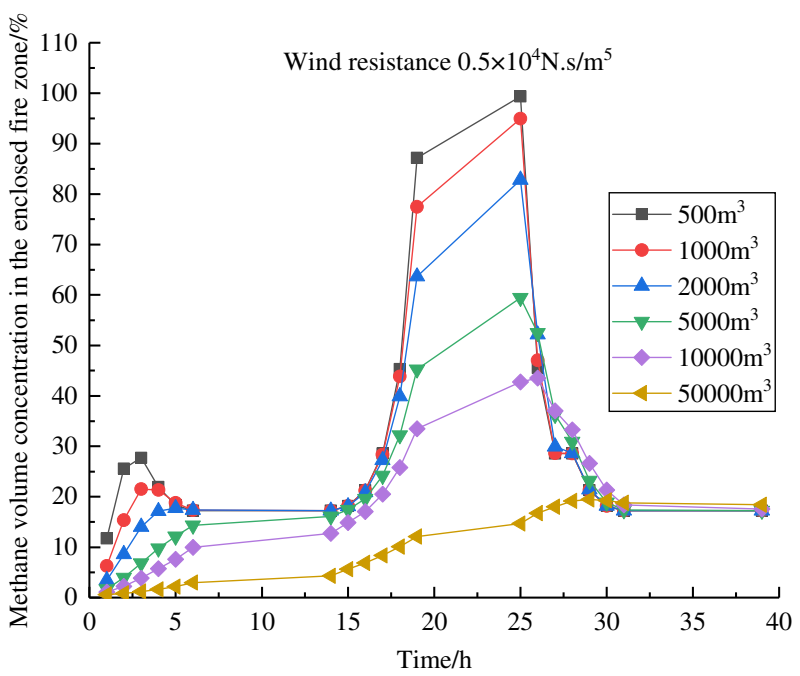

(b) Absolute gas emission in the fire zone $1 \mathrm{~m}^{3} / \mathrm{min}$

Fig. 11 Different gas emission, different fire zone volume, and small wind resistance, the changes of gas concentration in the fire zone with time after the completion of sealing at 19:00

completely closed at 13:00. It can be seen from the Fig. 12, $500,1000,2000,5000,10,000$ and $50,000 \mathrm{~m}^{3}$ fire zones reach the lower limit of $5 \%$ explosion time about $2.5,4.5$, $9.5,23,45,180 \mathrm{~min}$, respectively. The time to reach the maximum explosion concentration of $15 \%$ was about 8,16 , $31.5,78.5,150$, and $390 \mathrm{~min}$, respectively. The duration of explosion risk concentration was about 5.5, 11.5, 22, 55.5, 105, 210 min, respectively. In the Fig. 12b, 500, 1000, $2000,5000,10,000$ and $50,000 \mathrm{~m}^{3}$, respectively, fire zones reach the lower limit of $5 \%$ explosion time about at 25,50 , $100,190,280,430 \mathrm{~min}$, respectively. The time to reach the maximum explosion concentration of $15 \%$ was about 82 , 110, 260, 390, 440, and $450 \mathrm{~min}$, respectively. The

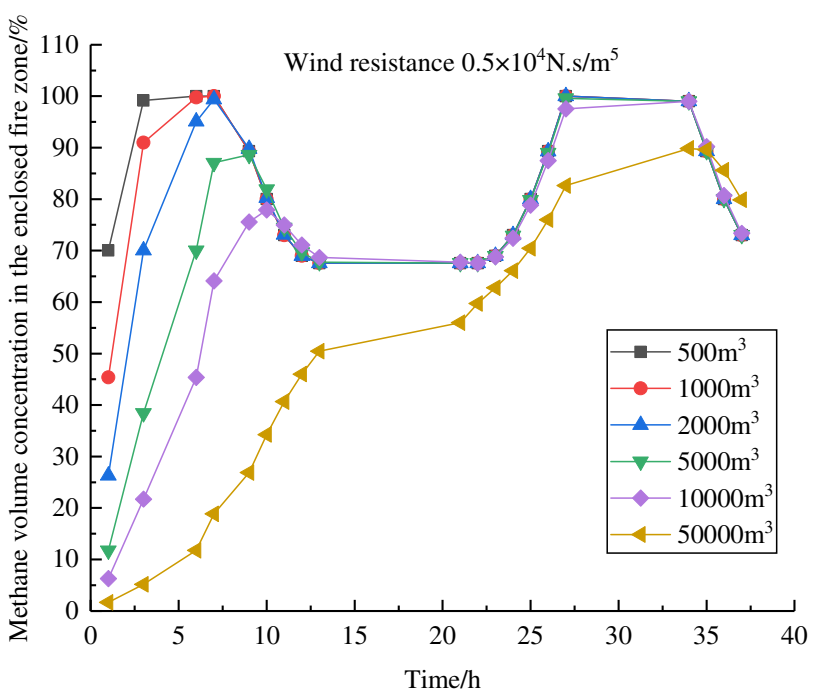

(a) Absolute gas emission in the fire zone $10 \mathrm{~m}^{3} / \mathrm{min}$

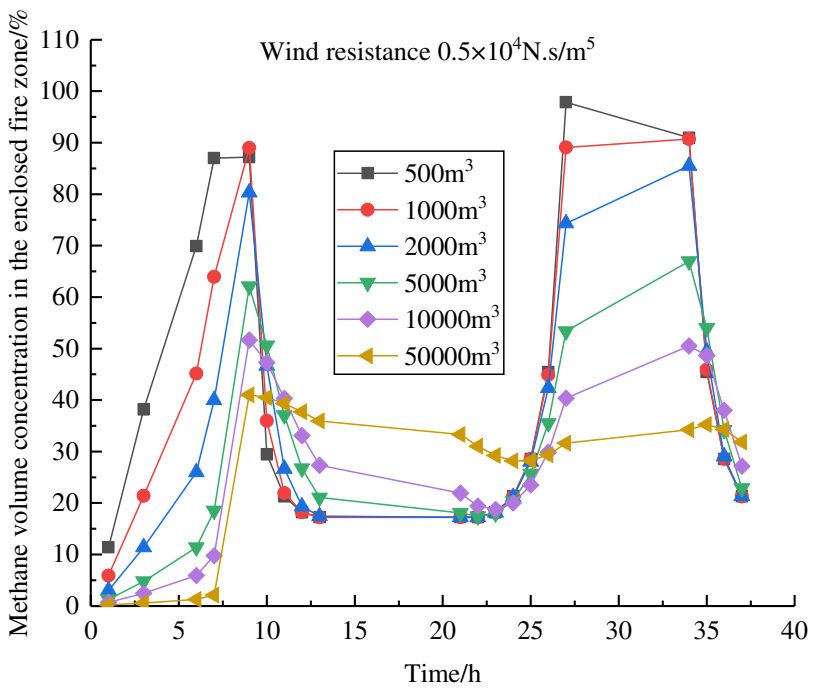

(b) Absolute gas emission in the fire zone $1 \mathrm{~m}^{3} / \mathrm{min}$

Fig. 12 The gas concentration in different fire zones, the volume of different fire zones, and the small wind resistance. The changes of gas concentration in the fire zone with time after the completion of sealing at 13:00

duration of explosion risk concentration was about 57, 60, 160, 200, 160, $20 \mathrm{~min}$, respectively.

Similarly, three different moments were taken to study the variation law of gas concentration in the initial stage of fire closure under the circumstance of $5 \times 10^{4} \mathrm{~N} \mathrm{~s} / \mathrm{m}^{5}$ fire zone wind resistance, as shown in Figs. 13, 14 and 15. Through comparative analysis, it can be seen that the fire zone with good sealing quality (large wind resistance) has better resistance to disturbance of atmospheric pressure fluctuation than the fire zone with poor sealing quality (small wind resistance). The fluctuation range is relatively small (within 30\%), and all of them are in non-explosive 


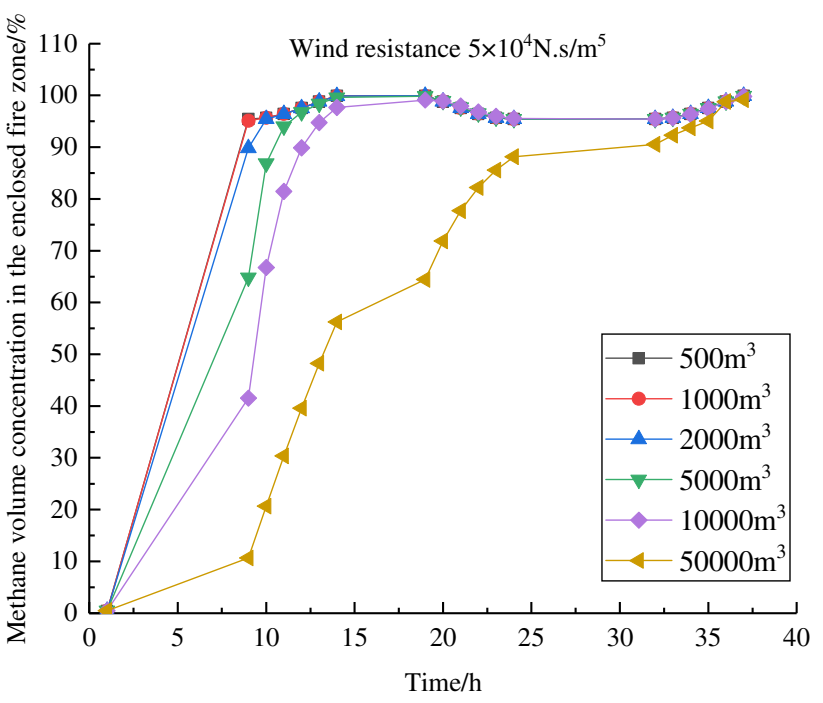

(a) Absolute gas emission in the fire zone $10 \mathrm{~m}^{3} / \mathrm{min}$

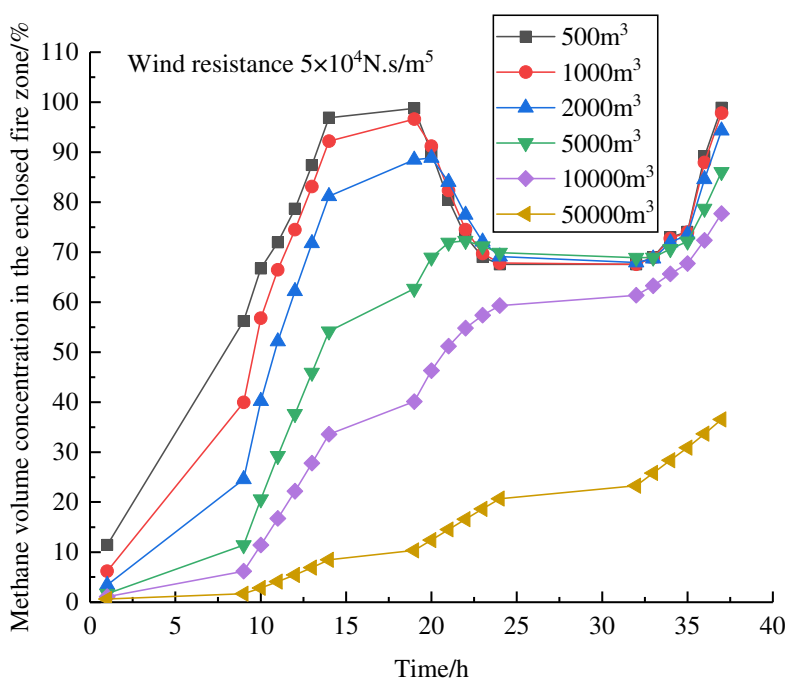

(b) Absolute gas emission in the fire zone $1 \mathrm{~m}^{3} / \mathrm{min}$

Fig. 13 Different gas emission, different fire zone volume, and large wind resistance, the changes of gas concentration in the fire zone with time after the completion of closing at 24:00 midnight

area. The rise of gas concentration in the inner side of wellsealed fire area mainly depends on the agglomeration of gas gushing out. The gas concentration in a small volume fire area will rapidly rise to the explosion limit range, quickly pass through and reach the non-explosive area, while the gas concentration in a large volume fire area will reach the explosion range after a long period of time, and maintain for a long time. The gas concentration in a small volume fire zone will rapidly rise to the explosion limit range, quickly pass through and reach the non-explosive area, while the gas concentration in a large volume fire zone will reach the explosion range after a long period of time, and maintain for a long time. Comparatively

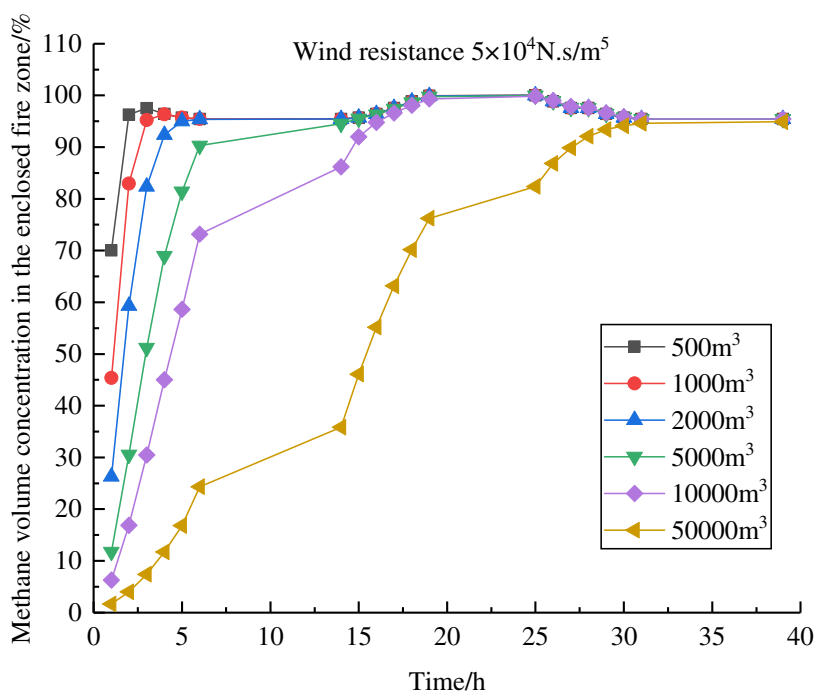

(a) Absolute gas emission in the fire zone $10 \mathrm{~m}^{3} / \mathrm{min}$

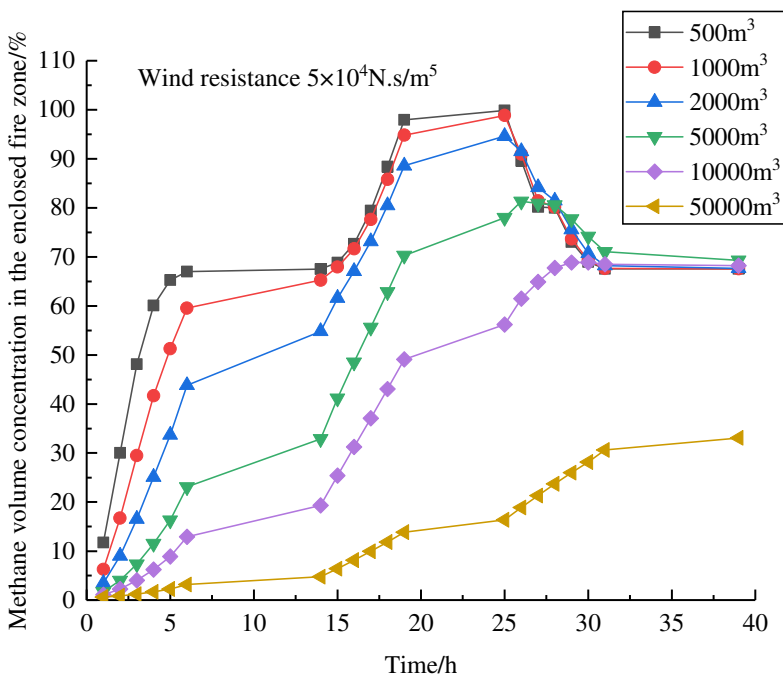

(b) Absolute gas emission in the fire zone $1 \mathrm{~m}^{3} / \mathrm{min}$

Fig. 14 Different gas emission, different fire zone volume, and large wind resistance, the changes of gas concentration in the fire zone with time after the completion of sealing at 19:00

speaking, the rising rate of gas concentration in the fire zone with a large amount of gas emission is much faster than that in the fire zone with a small amount of gas emission. The explosion limit is satisfied earlier, the explosion time period is shorter, and the danger is relatively smaller.

\subsection{Analysis on the influence of pressure fluctuation on gas explosion risk in the closed fire zone}

As it can be seen from Figs. 4, 5 and 6, in the initial stage of sealing, when the sealing quality of the closed wall is good and the absolute gas emission is high, the oxygen 
concentration will rapidly decrease to lower than $12 \%$, although there is a rebound without exceeding the limit. When the absolute gas emission was low, the oxygen concentration rebounded to higher than $12 \%$. For the poor sealing quality of the closed wall, no matter the absolute gas emission quantity is high or low, the oxygen concentration is higher than $12 \%$. The gas and oxygen concentration were analyzed with the cross analysis method at three different closed time points, as shown in Fig. 16.

Figure 16 is a cross analysis diagram of oxygen concentration and gas concentration according to the above analyses, with the maximum and minimum values

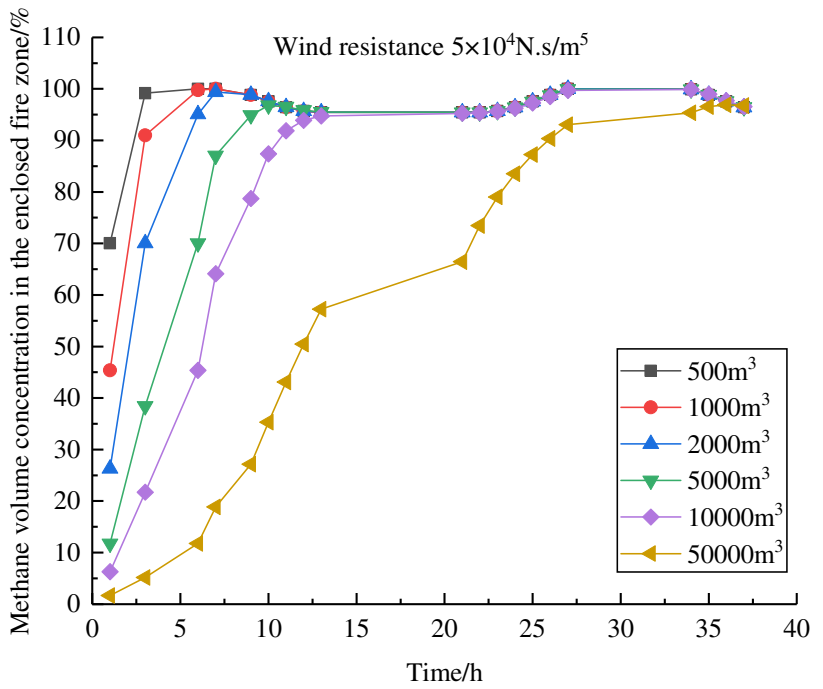

(a) Absolute gas emission in the fire zone $10 \mathrm{~m}^{3} / \mathrm{min}$

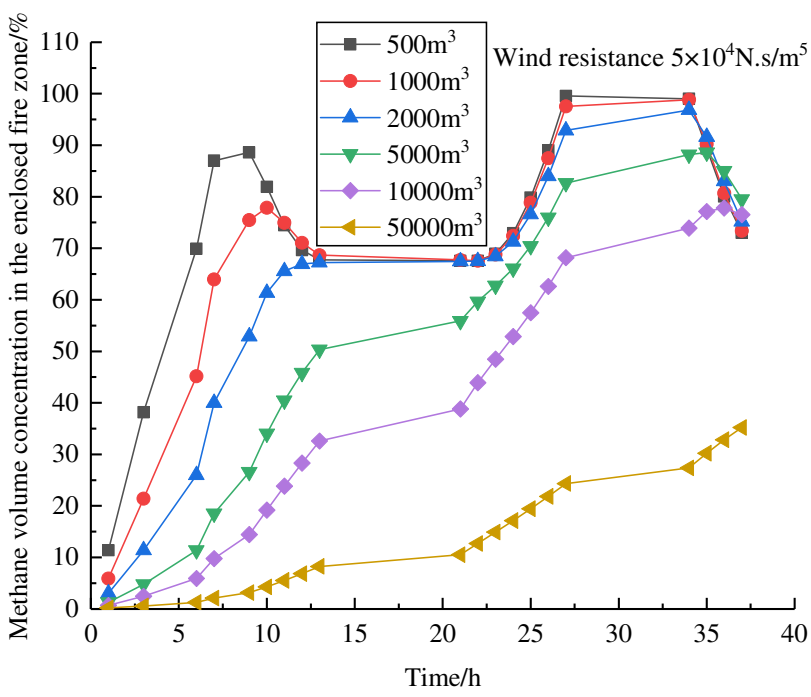

(b) Absolute gas emission in the fire zone $1 \mathrm{~m}^{3} / \mathrm{min}$

Fig. 15 The gas concentration in different fire zones, the volume of different fire zones, and the large wind resistance. The changes of gas concentration in the fire zone with time after the completion of sealing at 13:00

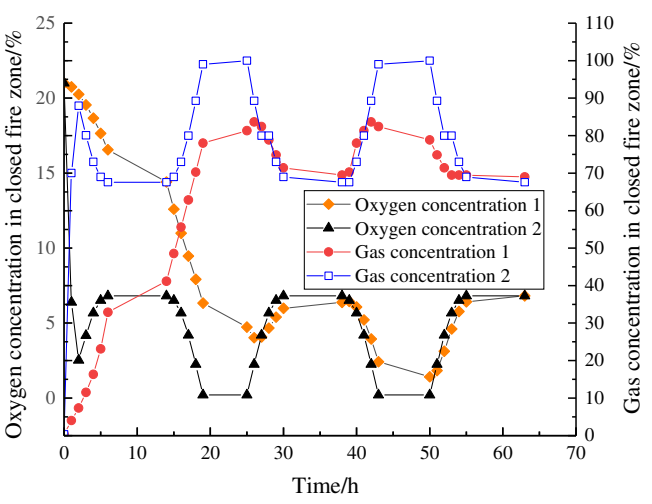

(a) Small wind resistance and large amount of absolute gas emission

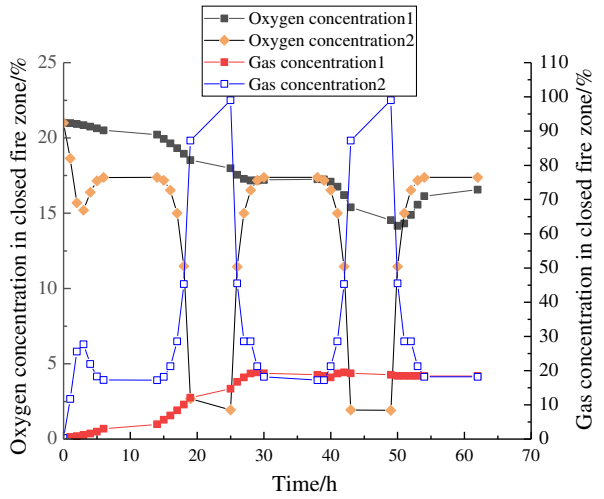

(b) Small wind resistance and small amount of absolute gas emission

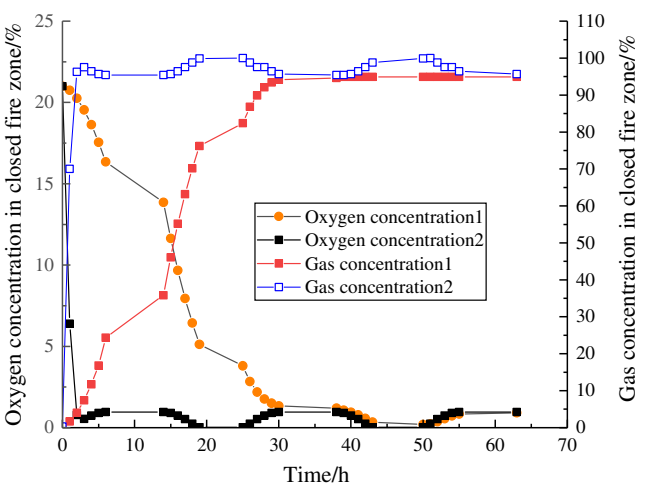

(c) Large wind resistance and large amount o fabsolute gas emission

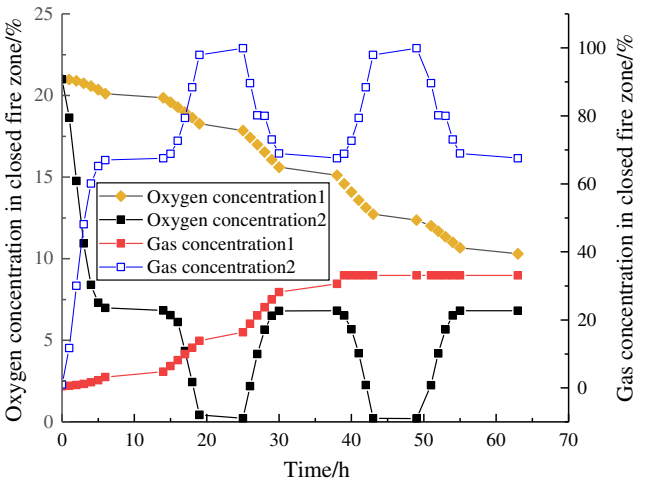

(d) Large wind resistance and small amount of absolute gas emission

Fig. 16 Scissor and fork analysis method for gas and oxygen concentration 
respectively, representing the two extremes of the analysis type, and the rest are right in somewhere of the middle. It can be seen from the figure that the explosion risk interval corresponding to the case where the wind resistance represented by Fig. 16a is small, the absolute amount of gas emission is large, and the wind resistance represented by Fig. 16c is large and the absolute gas emission amount is relatively small. The duration of the gas explosion in the closed fire zone is less affected by atmospheric fluctuations in the several minutes to 2 or $3 \mathrm{~h}$. The situations of small wind resistance and small absolute gas emission represented in Fig. 16b and the situations of large wind resistance and small absolute gas emission represented in Fig. 16d corresponded to relatively large gas explosion risk interval, which lasted for more than $10 \mathrm{~h}$ and was relatively affected by atmospheric fluctuations. Among them, the situation in Fig. 16b is particularly affected by fluctuations, mainly because the gas concentration will be affected by atmospheric fluctuations in the period of $17 \%-8 \%$, and the upper limit of the gas explosion is very close. If the external conditions are abrupt, it is highly probable that there is an explosion in an instant.

\section{Analysis and verification}

Zhou (2002) suggested that after the fire zone is closed, the internal oxygen concentration will gradually decrease and the gas concentration will gradually increase. After a certain period of time, these two will form an area with explosive risk inside the fire area. The difference from the research results is that the size of the enclosed fire zone and the quality of the closed fire zone are different. The time required to reach the explosion area is longer and the duration of the explosion is different. The studies of Niu et al. (2016) showed that different sealing sequences have a certain effect on the gas concentration inside the fire zone. It also creates explosive danger areas inside the fire zone. Zhai and Lai (2016) studied that after the fire area is closed, there is indeed a danger zone leading to explosion. What is different from the research results is that the rise and fall rate of gas and oxygen concentration are much faster, which means the conditions for gas explosion appear much earlier. However, its potential explosion duration is relatively short.

At the same time, on-site verification has been carried out in this paper in combination with engineering projects. The engineering background are two mines. The first one is a mine which the air pressure was measured in Fig. 1. The absolute gas emission of this mine is $12.8 \mathrm{~m}^{3} / \mathrm{min}$, and volume of fire zone is about $2500 \mathrm{~m}^{3}$, and the completion of sealing at about 24:00. The oxygen concentration of fire zone was measured about $40 \mathrm{~h}$ after sealing completed.
The results shows that the oxygen concentration fluctuates between $3 \%$ and $7 \%$, it's very close to our researches.

The other one is a mine of a large coal industry group in northern China with an approved production capacity of 1.5 million tons/year. The absolute outflow of the mine is $103.8 \mathrm{~m}^{3} / \mathrm{min}$, and the relative gushing amount is $21.9 \mathrm{~m}^{3} /$ t. The mine has a high gas capacity. Rectangular section is adopted in the roadway of this mine, with a net width of $5.0 \mathrm{~m}$, a net height of $3.6 \mathrm{~m}$, and a length of about $715 \mathrm{~m}$. The mining face volume is $12,870 \mathrm{~m}^{3}$, including the goaf volume. The fire area volume is larger than goaf volume, which belongs to the situation of the large fire zone. After the coal seam is self-ignited, the relevant technical department uses polyurethane foaming materials to seal the fire zone and close the fire zone at 12:00 on a certain day. After the completion of the sealing, the original monitoring sensor, beam tube and other means were used for gas sampling and chromatographic analysis of different positions inside the fire zone. The results showed that the polyurethane sealing quality is good, and the air leakage in the fire zone is very small, which can be regarded as the case of high wind resistance. After on-site observation, about $8 \mathrm{~h}$ after the closure was implemented, a gas explosion occurred in the closed fire zone. This showed that after $8 \mathrm{~h}$, the oxygen concentration and gas concentration inside the fire zone meet the necessary and sufficient conditions for the explosion. There is a high temperature area, which in turn causes a gas explosion. As it belongs to the large fire zone and closed at noon, it can be seen from the comparison of gas concentration 1 and oxygen concentration 1 in Fig. 16c that the oxygen concentration is higher than $12 \%$ and the gas concentration is between $5 \%$ and $15 \%$ in the $8 \mathrm{~h}$ interval after the closed zone is completed. There is a complete possibility of explosion. This indirectly proves the field value of the research results. Therefore, the closed time, the closed quality, etc. are critical to the steady state after the fire zone is closed.

All the above research results showed that the research results in this paper are similar with the results mentioned above to a certain extent, and have been verified by engineering projects, which have important guiding significance for the safe implementation of closed operation in coal mine fire zone.

\section{Conclusion}

(1) The fluctuations in the atmospheric pressure of the mine, the quality of the closed wall in the fire zone, and the amount of gas in the fire zone have an important influence on the gas concentration and oxygen concentration inside the closed fire zone. 
(2) Compared with the fire zone with poor airtight quality (high wind resistance), the fire zone with good airtight quality (low wind resistance) has better resistance to the disturbance of atmospheric pressure fluctuation with relatively small fluctuation range and is located in the non-explosive area. The increase of gas concentration and the decrease of oxygen concentration, inside of the closed fire zone with good quality, mainly depend on the accumulation of gas emission.

(3) The gas concentration inside the fire zone with poor airtight quality (small wind resistance) is easy to be disturbed by the external atmosphere, and the relative fluctuation is large. There are situations in which the conditions of the explosion are repeatedly reached or approached.

(4) The completion time of the fire zone closure has an important influence on the variation law and fluctuation of the inner gas concentration after the fire zone is closed. Especially, attention should be paid to the fire zone with poor airtight quality.

(5) The research results of this paper are highly similar with the results of relevant scholars according to the comparison. After the site verification, it showed that there is a good field practical value, which can effectively guide the safe development of closure work in the coal mine fire area.

Acknowledgements This research was funded by the National Natural Science Foundation of China (No. 51804054), Natural Science Foundation of Chongqing (CN) (No. cstc2019jcyj-msxmX0324), project of science and technology research program of Chongqing Education Commission of China (No. KJQN201801517), Research Fund of Chongqing University of Science \& Technology (No. ck2017zkyb001) and Open Cooperative Innovation Fund of Xi'an Institute of Modern Chemistry (No. 204-J-2019-0387). Thanks.

Open Access This article is licensed under a Creative Commons Attribution 4.0 International License, which permits use, sharing, adaptation, distribution and reproduction in any medium or format, as long as you give appropriate credit to the original author(s) and the source, provide a link to the Creative Commons licence, and indicate if changes were made. The images or other third party material in this article are included in the article's Creative Commons licence, unless indicated otherwise in a credit line to the material. If material is not included in the article's Creative Commons licence and your intended use is not permitted by statutory regulation or exceeds the permitted use, you will need to obtain permission directly from the copyright holder. To view a copy of this licence, visit http://creativecommons. org/licenses/by/4.0/.

\section{References}

Adam D, Alicja K (2018) Forecast of methane emission from closed underground coal mines exploited by longwall mining: a case study of Anna coal mine. J Sustain Min 17(4):184-194

Arif W, Kyuro S, Yuichi S, Yoshiaki S, Hiroyuki T, Kagemi U, Hiroyuki M (2015) Assessment of air dispersion characteristic in underground mine ventilation: field measurement and numerical evaluation. J Process Saf Environ Prot 93(1):173-181

Deng C, Wang J, Hong L (2004) Gas transfer law in closed fire zone of a coal mine. J Liaoning Tech Univ 23(3):296-298

Duan Y, Zhou X, Ding X et al (2010) The methane distribution law of closed fire zone when pumping inert gas. J China Coal Soc 35(1):81-84

Guo X (2016) Analysis of the causes of breathing effect of goaf and research on gas control technology. Energy Technol Manag 41(4):24-26

Jiao Y, Duan Y, Zhou X et al (2012) Coal mine fire closed gas explosion induced by spontaneous combustion process of rules. J China Coal Soc 37(5):850-856

Li J (2012a) Study on breath phenomenon and prevention technology in goaf. J Shaanxi Coal (6):32-34

Li B (2012b) Cause analysis of breathing in mined-out area based on SF6 detection technology. J Shanxi Coal 32(8)

Niu H, Deng J, Zhou X et al (2013) Law of gas accumulation and analysis of danger of gas explosion during sealing fire zone in coal mine. J Cent South Univ (Science and Technology) 44(9):3918-3924

Niu H, Deng X, Li S et al (2016) Influence of closed sequence on distribution of gas in coal mine fire zone. J Cent South Univ (Science and Technology) 47(9):3239-3245

Shi G, Zhou T, Liu M et al (2017) Numerical analysis on gas explosion hazard during the process of fire zone sealing in coal mine. J China Univ Min Technol 46(5):997-1006

Wang J, Deng C, Ding B (2003) Study on heat transfer in close fire zone of coal mine. J Liaoning Tech Univ 22(4):452-454

Wang H, Feng C, Wang Z et al (2014) Dangers and critical parameters of inert gas injection during mine fire sealing. J China Coal Soc 39(z1):117-122

Zhai X, Lai X (2016) Rapid prediction method for explosion hazard in gas mine after sealing fire working face. J China Coal Soc 41(9):2251-2255

Zhang X, Xu J, Liu J et al (1999) High gas mine hair closed fire zone when the gas explosion hazard prediction. J Xi'an Min Inst 19(2): $15-18$

Zhou X (2002) Mine fire prevention. China University of Mining and Technology Press, Xuzhou, pp 146-160

Zhou J (2018) Study on gas variation law in mine closed fire area. J Coal Technol 37(3):185-187

Zhou X, Meng L, Shi M et al (2013) Influences of sealing fire zone in high gas mine on impact factors of gas explosion limit. J Explos Shock Waves 33(4):351-356

Zhou X, Li C, Zhang L et al (2015) Closed during fire gas migration law of numerical simulation. J Geol Disasters China Prev J 26(2):116-122

Zhu L, Zhou X, Xie J (2008) Analysis of sealed state and standard fire. J Coal Eng 11(7):68-70 